\title{
AS CADEIRAS DO CANCRO HEREDITÁRIO: COMPREENDER O TEMPO E A DOENÇA COM DESENHO ETNOGRÁFICO CRIATIVO
}

\author{
Susana de Noronha
}

\begin{abstract}
Resumo
Dando uso à ilustração científica, este texto tem como objetivo compreender a forma como o tempo é vivido, compreendido e gerido na doença oncológica hereditária, analisando a estória de cancro da mama de uma mulher Portuguesa portadora de mutações BRCA1/2. Desdobrado entre experiência vivida, antropologia e arte, este texto resulta de um exercício qualitativo transdisciplinar, introduzindo os saberes do corpo, a palavra dita e o desenho etnográfico criativo no centro da investigação, usando-os como recursos metodológicos e heurísticos. Partindo da narrativa recolhida em entrevista informal, propõe-se o uso de metodologias visuais e criativas, ambicionando uma compreensão reforçada da doença oncológica. Combinando texto e imagens, analisaremos as múltiplas aceções de tempo que permeiam esta estória, procurando as experiências, usos e sentidos dos momentos de espera, interrupção, lentidão, atraso, urgência e aceleração, antes, durante e depois da doença e do tratamento, usando e desenhando a cadeira, enquanto objeto concreto e metáfora, para lhes dar forma. A espera emerge como a experiência mais relevante para perceber a sua estória de cancro hereditário, ligando passado, presente e futuro num sofrimento que secundariza a dor física.
\end{abstract}

\section{THE CHAIRS OF HEREDITARY CANCER: UNDERSTANDING TIME AND ILLNESS USING CREATIVE ETHNOGRAPHIC DRAWING}

\begin{abstract}
Using scientific illustration, this article aims to examine how time is experienced, understood, and managed in hereditary malignancies, analysing the breast cancer story of a Portuguese woman with $\mathrm{BRCA} / 2$ mutations. Blending lived experience, anthropology, and art, this text results from a transdisciplinary qualitative exercise, incorporating embodied knowledge, speech, and creative ethnographic drawing at the core of the research, using them as methodological and heuristic resources. Based on a narrative collected in an informal interview, it suggests the use of visual and creative methodologies aimed at a reinforced understanding of cancer. Combining text and images, we will analyse the multiple meanings of time that permeate this story, searching for the experiences, uses, and meanings of moments of waiting, interruption, slowness, delay, urgency, and acceleration, before, during and after illness and treatment, using and drawing chairs, as concrete objects and metaphors, to give them form. Waiting emerges as the most relevant experience to understand her hereditary cancer story, linking past, present, and future within a form of suffering that minimizes physical pain.
\end{abstract}


INTRODUÇÃO: O TEMPO DO CANCRO, DO CONTEXTO AOS TEXTOS

Enquanto realidade sentida e pensada, que importância tem o tempo para quem vive o cancro no corpo e na carne? Que experiências, sentidos e usos se encastram no tempo antes, durante e depois de uma doença oncológica? De que forma são vividos e pensados os dias e datas de exames, diagnósticos, internamentos, ciclos de tratamentos, cirurgias, reconstruções e consultas de rotina? A literatura das Ciências Sociais e Humanas, sublinhando aqui a Antropologia e a Sociologia na estruturação deste artigo, tem apontado precisamente para o entrecruzamento dos tempos da vida, do corpo e do cancro. Sabendo que a experiência do cancro é "global, mas não uniforme" (Burke \& Mathews, 2017), atravessada pelas muitas variações históricas, socioculturais, económicas, geográficas e ambientais que marcam a sua etiologia, deteção, tratamento e acompanhamento, o tempo que temos varia e as experiências do mesmo dependem do contexto e do lugar (Araújo, 2012). A forma como vivenciamos, compreendemos e gerimos o tempo, depende também da nossa posição e participação situada dentro da doença, sejamos nós pacientes ou resistentes (Hauge, 2015), familiares, prestadores de cuidado ou terapeutas (Zerubavel, 1979). Depende ainda daquilo que somos, temos e fazemos, género, idade, família, profissão, rendimento, entre outros posicionamentos e possibilidades.

Relativamente à doença oncológica, as experiências que vivemos e as estórias que contamos inserem-se numa tessitura de construções sociais e expressões culturais onde o tempo assume uma relevância central (Adam, 1994, 2013; Hall, 1984). As narrativas de resistentes oncológicas/os, enquanto veículos de conhecimento vivido, permitem-nos compreender a doença enquanto processo encastrado nos tempos de um corpo, biografia e contexto particular. Se o cancro pode ser vivido como uma disrupção biográfica e temporal, desarranjando a pessoa que somos e o tempo que temos, as narrativas que estruturamos são exercícios de reordenação, desdobrando a experiência da doença numa sequência com princípio, meio e fim, datando e situando, criando controlo e sentido. Estas narrativas não se reduzem à palavra dita ou escrita, podendo assumir o formato desenhado, pintado, fotografado ou esculpido, entre outras configurações da visualidade criativa (Noronha, 2009). Analisando estórias de cancro nas artes plásticas e visuais, procurando as ligações entre doença e tempo, torna-se claro que a experiência incorporada destas realidades emerge de uma mistura indivisa de corpos, espaços e objetos, modelada pelas dimensões sociais, culturais, relacionais e materiais da nossa existência (Adam, 2013; Noronha, 2015).

Atravessando algumas das representações mais frequentes nestas narrativas (Noronha, 2015), as pulseiras de identificação hospitalar e as páginas de relatórios médicos dão-nos imagens de corpos em tempo de mudança, reclassificados como doentes num determinado ano, mês, dia e hora. As cadeiras de salas de espera e as batas também marcam os episódios de exames diagnósticos e internamentos, remetendo para o momento em que a vida se encastra nos lugares e temporalidades hospitalares. Feridas suturadas resultam das horas passadas nas mesas de cirurgia, num tempo usado por outros sobre os corpos anestesiados, já transformados ao acordar. As camas de enfermaria apontam 
para os dias de recobro, feitos de dor e dependência, um tempo de desconforto, sem grande descanso. Entrando nos ciclos de quimioterapia, as bombas infusoras marcam as horas e os dias passados entre gotas de medicação e efeito secundário, entre o vómito e a vontade de ganhar saúde. As imagens de corpos encostados a aceleradores lineares, apesar dos poucos minutos de exposição à radiação, remetem para a duração do seu efeito, da pele queimada às camadas de carne afetadas para a vida. Cabeleiras, lenços e chapéus enfeitam meses de tratamento, arrumados depois, no retorno dos cabelos e pêlos, num corpo e tempo sem cancro. Para quem carrega malignidades metastizadas ou terminais, aquietando-se nos seus últimos dias, os sofás e camas multiplicam-se e enchem o tempo que resta. As práticas criativas, visuais e artísticas conseguem assim traduzir, para um formato partilhável e inteligível, o tempo vivido do adoecimento, do tratamento, da remissão, da recidiva, do decaimento e da morte, mostrando a sua relevância para a compreensão do cancro.

Em cada ano, Portugal tem 50.000 novos casos de cancro e quase 29.000 mortes divididas pelos 12 meses (Miranda \& Portugal, 2016). Recolher parte destas estórias, analisando as suas particularidades, pode fornecer o conhecimento para uma compreensão das experiências e conceções destas/es resistentes. Contudo, aquilo que encaixamos na palavra cancro é diverso e alargado, dos muitos órgãos afetados por malignidades aos múltiplos formatos que a doença oncológica pode assumir. Mesmo quando referimos o comum carcinoma da mama, estamos a falar de um conjunto heterogéneo de patologias e experiências, carcinoma ductal, lobular ou inflamatório, do estádio o ao IV, in situ, invasivo ou metastático, com ou sem receptores hormonais, onde pesam os factores de risco comportamentais e as particularidades de um corpo, idade, sexo e herança genética. Biomedicamente, o cancro da mama é entendido como uma doença com remissões e recidivas, um risco temporal estendido a duas décadas. Contudo, a Ciência Social pode entendê-lo como uma realidade crónica, não no sentido de sintomatologia ou tratamento contínuo, mas apontando para a perenidade do seu impacto físico e biográfico.

Este artigo comenta e traduz para desenho etnográfico criativo uma experiência de cancro da mama hereditário, analisando as especificidades de uma doença que pesa sobre o corpo mesmo antes de diagnosticada, apertando passado, presente e futuro, revelando a importância do tempo e da espera nas malignidades de origem genética. Recolhendo experiências e narrativas na primeira pessoa, a Ciência Social desdobra as particularidades das experiências vividas sob a ameaça das mutações $B R C A 1 / 2$, que aumentam a predisposição de desenvolvimento de cancro da mama e do ovário, bem como o risco de uma recidiva. Relativamente a estas mulheres e estórias, a investigação em Ciência Social enfatiza o agudizar do medo, da ansiedade e das perceções de inevitabilidade, vulnerabilidade e incerteza, o risco permanente de doença (Hallowell \& Lawton, 2002), os exames repetidos, o futuro ambíguo (Dean, 2016). A experiência familiar de cada uma, muitas vezes atravessada por episódios e memórias de cancros e mortes traumáticas de mulheres próximas, marca as perceções da doença e as decisões tomadas, dos testes e consultas médicas às mudanças feitas na vida (Hallowell \& Lawton, 2002). Para além dessa herança experiencial de doenças, dores, mortes, perdas, 
alegrias e vitórias vividas em família, também se interroga e comenta a gestão diária do risco, os saberes e práticas de resistência partilhados, as expectativas depositadas na genética e na medicina, o uso do tempo e da ação atempada, da vigilância à deteção (Mendes, 2004).

Contudo, a literatura mostra que para muitas das testadas, o cancro transforma-se na única certeza, "não é se, é quando" será diagnosticado (Dean, 2016). "Esperar que o cancro chegue" é um processo carregado de efeitos psicológicos, emocionais e relacionais (Hesse-Biber, 2014), uma estória de medo e ansiedade, vivida na antecipação. Os protocolos, exames de rotina e soluções apontadas pelo conhecimento médico não empoderam nem protegem as "portadoras" de mutação genética. Elas sentem-se como pacientes em espera, numa condição que não podem prevenir nem controlar, uma instabilidade que marca e muda escolhas e decisões, das relações pessoais às intervenções feitas nos corpos e órgãos (Hallowell \& Lawton, 2002). Os recentes testes genéticos, com ambição preventiva na sua busca por mutações, produziram um "antes" da doença, uma determinada temporalidade que passou a fazer parte das narrativas de pacientes, resistentes e mesmo das já chamadas "previventes", mulheres que optam pela mastectomia e ooforectomia antes da manifestação do cancro. Ainda hoje, os métodos de prevenção da doença oncológica são praticamente inexistentes, deixando por dizer de que forma se evitam os cancros "anunciados" por estas mutações, como se travam as suas recidivas.

A investigação também nos demonstra como as tentativas de controlar a nossa saúde futura, influenciando o risco de cancro hereditário ou genético, são uma ilusão, uma crença com profundas consequências na forma como resistentes oncológicas e mulheres com estórias de cancro em família conduzem as suas vidas (Finkler, 2003). Para quem vive um cancro antes dos 40 , aos 20 ou 30 anos de idade, fica a dúvida, depois do tratamento, se o cancro voltará, se o fim do futuro está mais perto, apertando identidades e escolhas, "nem doentes nem livres de doença", num momento liminar que não passa (Rees, 2016), que está para ficar. Neste artigo, a estória que se conta corrobora e prolonga uma grande parte das considerações teóricas da Ciência Social sobre o cancro da mama hereditário, mas acrescenta-Ihe uma leitura em falta. A mulher que fala diz que é possível acelerar e alargar a vida quando mutações genéticas e carcinomas da mama nos querem parar e apertar. Pondo as mamas e as dores de lado, traz o tempo e "as esperas" para o centro do debate (Mulcahy, Parry \& Glover, 2010), sublinhando a sua importância para uma compreensão adequada da doença.

Embora vividos como uma única experiência, Alexandra Silva teve cancro da(s) mama(s), carcinoma ductal invasivo na mama direita e in situ na esquerda, com mastectomia radical modificada e uma mastectomia subcutânea com reconstrução imediata. As suas palavras desafiam noções simplistas sobre o sofrimento durante o tratamento, secundarizando a dor física. Na sua estória de doença "o pior é a espera", esperar por exames, relatórios e resultados, cirurgias, ciclos de quimioterapia e reconstruções, mais desesperante que as dores do pós-operatório. Das cadeiras das salas de espera às cadeiras de casa, onde o tratamento não avança e a doença não pára, as "vésperas" e 
- "antes" são momentos de extrema ansiedade para uma mulher que queria acabar e fechar a sua estória de cancro. Esperas e cadeiras adiam o fim de tudo, gastando tempo no calendário. Procurando contrariar as paragens de todas as esperas, a estratégia de resistência de Alexandra foi nunca parar, quis ser, saber e fazer mais, viver intensamente e acelerar acontecimentos, conhecer gente, sítios e coisas, entre família, amigos e conhecidos, falando frequentemente sobre o seu cancro da mama, expondo e partilhando detalhes de carcinomas, tratamentos, cicatrizes e reconstruções. Portadora das mutações $\mathrm{BRCA}_{1} / 2$, a pior espera é a que continua a viver todos os dias, a volta do cancro, uma segunda vez, tão incerta como pesada, sem data marcada.

\section{Abordagem Concetual e metodológica}

Este artigo resulta de uma investigação antropológica mais alargada, centrada na recolha de estórias de mulheres Portuguesas com diferentes experiências oncológicas, analisando a forma como o adoecimento, a resistência e a morte são vividos e pensados (Noronha, 2019). Para uma compreensão reforçada do cancro, privilegia-se os conhecimentos incorporados de quem o vive e sente, pacientes, resistentes e família, atravessando diferentes faixas etárias e doenças oncológicas, do estádio I ao IV. Enquanto investigação baseada na arte, este projeto carrega também a ambição de desmantelar estereótipos sociais encastrados nas doenças oncológicas. Recolhendo as estórias daquelas que resistem, o uso de ilustração científica ou desenho etnográfico criativo, dando uma forma pública a estas experiências, tenciona preencher um hiato não só no entendimento científico do cancro, mas também no conhecimento e na imagética coletiva da sociedade Portuguesa, procurando providenciar a doentes e famílias um contexto relacional e comunitário solidário. Uma Ciência Social ilustrada, combinando texto e imagem, utilizando metodologias visuais e criativas, poderá assim facilitar e reforçar o impacto e os resultados sociais da investigação em saúde e doença.

Nivelando experiência vivida e Ciência Social, juntando-lhe a arte, este projeto introduz os saberes do corpo, a palavra dita e o desenho no centro da investigação, usando-os como recursos metodológicos e formas de conhecimento. Para além do potencial para democratizarem a ciência, produzindo um conhecimento mais acessível, que pode ser lido e visto, as metodologias visuais criativas podem alargar a forma como os estudos sociais e culturais compreendem e agem sobre a realidade, diversificando aquilo podemos dizer, mostrar e fazer. Recusando o seu posicionamento meramente apendicular, aproveito assim a carga ontológica (Noronha, 2009), heurística, epistemológica e performativa (Gell, 1998; Noronha, 2009) das práticas artísticas e visuais da ilustração, entendendo-as como possíveis acrescentos de experiência, ou seja, parte do modo como a doença pode ser sentida, entendida e gerida, salientando a importância do tempo para uma compreensão da mesma. Ligando a Antropologia da doença (Mattingly \& Garro, 2001) às possibilidades de hibridação entre a Etnografia, a Arte (Schneider \& Wright 2005) e os métodos visuais (Banks \& Zeitlyn, 2015), enfatizo o que encontramos na sua mistura (Noronha, 2015). Pode a Antropologia e o desenho etnográfico criativo, partindo 
da experiência vivida e do conhecimento incorporado (Csordas, 1994) de uma mulher, produzir sentido sobre o tempo e a doença (Bell, 2006; Noronha, 2009), dar forma à espera e às experiências que nela se sentam? Como podemos converter as experiências do cancro e da espera para uma soma indivisa de fala, texto e imagem?

Para cumprir os objetivos híbridos e intersubjetivos desta análise, a entrevista com Alexandra Silva foi conduzida como uma conversa informal, no conforto da sua residência, permitindo que a mulher entrevistada guiasse a estória emergente, recusando um questionário predefinido e um lugar externo à sua vida. A conversa foi gravada em ficheiro áudio e posteriormente transcrita, procurando os momentos e realidades sublinhados pela própria entrevistada. Juntando fala, texto e imagem, numa soma indivisa e nivelada, parte-se da estória contada e da mulher que a conta, da sua experiência e conhecimento, dando forma àquilo que é dito pelas suas palavras, entre texto e imagem. Ao reescrever e redesenhar esta estória, o conceito e a prática da ilustração em ciência foram também repensados, aumentados pela imaginação e pela metáfora. Trazendo as regras da arte para uma versão mais livre e criativa do desenho etnográfico, a metáfora encontra encaixe na realidade dos factos e na escrita da ciência, alargando e facilitando a nossa compreensão. Resultando da conversa, os desenhos são entendidos como produtos colaborativos e coautorados, recebendo também o nome da minha interlocutora, nivelando escrita e fala, investigadora e resistente oncológica. Os títulos que acompanham os desenhos também saíram da sua voz, frases que resumem e explanam momentos centrais da sua experiência e estória.

\section{ESPERAR PELO DIAGNÓSTICO: DAS MUTAÇões GENÉTICAS AO CARCINOMA}

"Eu sou a Alexandra que teve um cancro. Está no meu ADN". Na família de Alexandra, o cancro avançou entre gerações, da avó para a tia e a mãe. Neta, filha e sobrinha de mulheres com cancro, Alexandra recebeu o resultado do seu teste genético em setembro de 2007, sabendo-se herdeira das mutações BRCA1/2. "Aquilo já abalou a Alexandra. Isso fez-me mudar um pouco a minha perceção sobre o futuro, porque no dia em que eu soube que tinha a mutação genética, eu achei que ia efetivamente ter um cancro da mama". O relatório trazia agarrado um segundo papel, o chamado protocolo, ditando o calendário de exames que Alexandra teria de seguir para o resto da vida, dividindo os anos entre ecografias, mamografias e ressonâncias magnéticas. "Eu não estou para isto. Como é que vou fazer isto todos os anos da minha vida até ao fim dos meus dias? Eu quero que me tirem as mamas! Aquilo é um papel. Eu não sou um papel!". Alexandra não queria que aquela folha definisse o seu tempo e comandasse a sua vida. Alexandra diz e sabe que as mulheres não são todas iguais, nem as irmãs, mas o papel colocava-as entre a multidão, dando-lhes "uma probabilidade futura de cerca de $85 \%$ até aos 85 anos de ter um cancro da mama". Mas os dois papéis, relatório e protocolo, mudaram tudo, mesmo o presente, e quando Alexandra chegou a casa já nada era igual. "Com este papel à frente", Alexandra já não era a mesma, mas uma outra, mudada a partir de dentro. 


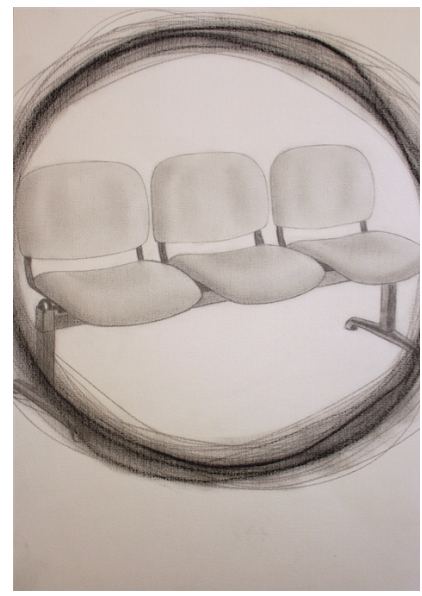

Figura 1: Eu não sou um pape!! [Grafite e carvão sobre papel]

Fonte: Susana de Noronha e Alexandra Silva (2017)

Em outubro de 2007, Alexandra fazia a primeira ecografia e mamografia, já seguindo o protocolo, tinha "uma mama grande, farta, muito fibrosa, mas tudo impecável!" Mudou o ano e Alexandra mudou de hospital, dos Hospitais da Universidade de Coimbra para o Instituto Português de Oncologia (IPO) da mesma cidade, fazendo novos exames, uma ressonância magnética marcada para 3 de março. "Fui fazer a ressonância, uma coisa relativamente simples, e fui-me embora descansadinha". Dias depois, avessa às esperas, passou pelo IPO, procurando a sua médica, que lhe disse que tinham de "ver aquilo com cuidado" porque havia qualquer coisa que não estava bem. "Recordo-me de ser marcada uma biopsia. Eu sei que me doeu. Esse é o lado físico da coisa, mas isso passa. Do que eu me lembro é da ansiedade das vésperas, da ansiedade de entrar na porcaria sala e depois sair de lá e esperar até ao dia em que vem o resultado. As piores experiências que eu tive. O pior é a espera! Aquele stress, aquela dor da ansiedade!" Alexandra esperou para saber que teria de fazer tudo de novo. O resultado da biopsia foi negativo, mas o médico não tinha a certeza de ter puncionado no sítio certo. Reencaminhada para o Centro de Senologia de Lisboa, guardou as palavras que saíram consigo da sala, "isto não tem bom ar, quando mais não seja, isto vai ter que ser tirado!" Acompanhada do protocolo, Alexandra saiu com muitas dúvidas e perguntas sobre os dias seguintes, o futuro a curto prazo.

O que é suposto eu fazer? Eu já não sei como é que vai ser o dia de amanhã. A qualquer hora ia haver o telefonema a dizer o resultado daquela análise. Alguém decidiria por mim o que ia ser feito em relação à minha vida.

Eu sempre fui um bocado dada a depressões, sempre imaginava o meu futuro como algo de negro, que alguma coisa não muito positiva me iria acontecer. Tanto que nunca fui uma pessoa de fazer projetos de longo prazo. Talvez seja defeito... feitio?! 


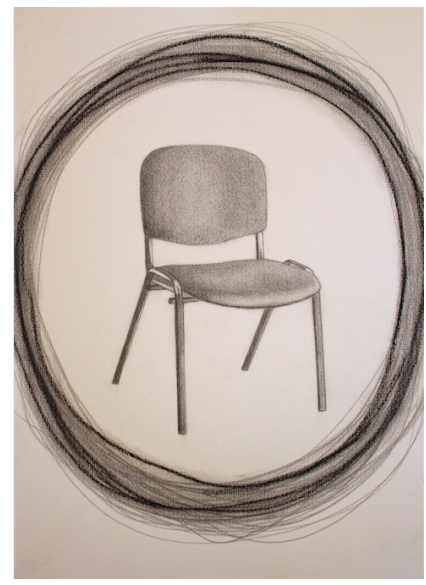

Figura 2: O pior é a espera! [Grafite e carvão sobre papel]

Fonte: Susana de Noronha e Alexandra Silva (2017)

Alexandra voltou para casa e continuou à espera, deixando um pedaço de si para trás, a 200 quilómetros. Dia 11 de abril, sexta-feira, uma amiga levantou o envelope com o relatório, ainda fechado. O telefone tocou e embora Alexandra o quisesse atender, parar com a espera, o resultado não foi o esperado. O resultado foi positivo, era um carcinoma, um crescimento em tudo negativo, na mama direita, na vida inteira.

Houve ali aqueles 10 minutos de espernear dentro de um carro fechado, de espernear e gritar... porquê? Depois paras e respiras... Eu sei muito bem porquê! Há aquele momento de raiva e de questionamento, mas a causa para mim estava muito bem localizada. Eu tenho uma mutação genética. Toda essa explicação científica permitiu-me sossegar e não andar à procura de nenhuma outra.

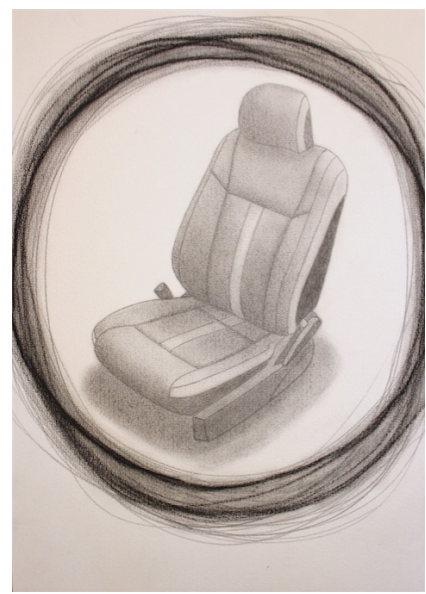

Figura 3: Dez minutos de espernear e gritar [Grafite e carvão sobre papel] Fonte: Susana de Noronha e Alexandra Silva (2017) 
A negrura que Alexandra esperava saiu do resultado positivo de cancro aos 28 anos, já em 2008. Para além de companheiro, Alexandra tinha casa comprada, mestrado quase terminado, bolsa de doutoramento à espera e uma carreira pela frente em história da cultura. O "defeito" iria mudar-lhe o feitio por fora e por dentro, e todos os projetos de curto, médio e longo prazo foram tocados ou trocados.

No dia seguinte, sábado, 12 de abril, Alexandra estava de visita à casa dos pais.

O pior é contar aos pais! Nada me custou como contar aos meus pais. A pior coisa que eu fiz na minha vida... é uma memória que está aqui todos os dias. Dizer aos meus pais... eu tenho um cancro!

Alexandra juntou as duas piores coisas, esperar e contar, sentada na cadeira, até ao fim do almoço. Não quis que ninguém perdesse apetite, queria ter uma "refeição em paz", sem carcinoma em cima da mesa. A espera foi dura mas as palavras saíram, "já sei o resultado do exame", e não teve de dizer mais nada para que os pais percebessem que tinha a doença, o cancro que todos já conheciam. Os carcinomas já são de família, mesmo que ninguém os queira por perto. O pai, "pessoa extremamente fechada e muito direito", olhou para ela, deixou-se curvar e chorou. A mãe dizia "eu é que vos passei isto. Eu é que sou a culpada disto!". Foi Alexandra que os reconfortou com palavras. "É uma coisa recente. Eu vou tratar-me. Mãe pára, não tens culpa de nada disto! Aqui não há culpas. Isto é a natureza. Tenham lá calma. As coisas vão correr bem". Nesse momento, Alexandra, mulher feita, filha crescida, fez-se grande, agarrando a vida que lhe tinha sido dada. "Naquele exato momento, eu apercebi-me que eu devo aos meus pais sobreviver de cara alegre, ao que quer que venha aí. Eles merecem isso!".

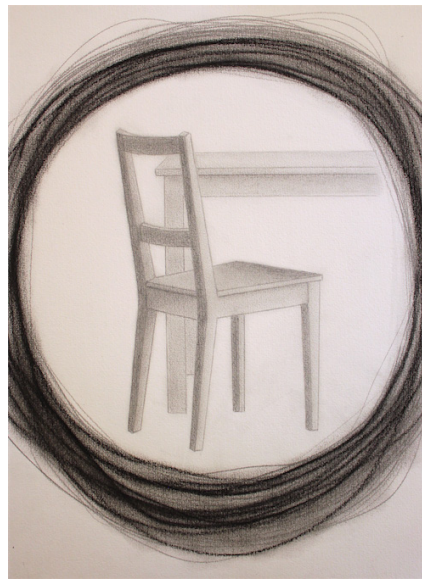

Figura 4: O pior é contar aos pais! [Grafite e carvão sobre papel]

Fonte: Susana de Noronha e Alexandra Silva (2017)

\section{ESPERAR PELO ÚlTIMO DIA DE TRATAMENTO: MASTECTOMIAS E CICLOS DE QUIMIOTERAPIA}

Já internada, o dia 20 de maio madrugou e Alexandra levantou-se para tomar um banho de Betadine, tingida por fora, mal preparada por dentro, tentando perceber, em poucos minutos, um corpo e uma vida em transformação. 
Lembro-me de um momento de pânico... tu vais sozinha com aquela batita para a casa de banho. É o ultimo momento de introspeção que tens. Sabes quando estás no limiar do desespero... o que é que me está a acontecer? Eu com esta bata e estas mamas que daqui a bocado já não vão estar aqui... muito surreal. Teres tempo para fazer essa reflexão é muito doloroso.

Já na sala de cirurgia, deitada e quieta, Alexandra deixou cair os olhos no relógio de parede enquanto a anestesista lhos tentava fechar. Alexandra acordou a perguntar pelas horas, até perceber que as dores que tinha lhe pediam todo o seu tempo e atenção. "Acordei a morrer de dores, no peito, em toda esta zona das costas. Acho que a cirurgia foi bastante longa. Eu fiz a mastectomia radical na mama direita com remoção de gânglios, e mastectomia com reconstrução imediata da esquerda". Levantar o corpo e sair da cama puxou dores maiores. Parte do seu pânico era não conseguir comer ou "fazer xixi", sentir-se parada naquilo que queria ou tinha de fazer.

Houve ali uma altura que me vieram tentar levantar. Foram as piores dores, coisa horrível... muita dor mesmo. Não conseguia fazer xixi... fisicamente foi um processo obviamente doloroso. Depois, lá pedi para me levarem à casa de banho porque não conseguia fazer na arrastadeira. Mas não me conseguia segurar e aquela debilidade também é uma coisa que marca... a dependência. Uma coisa que me marcou muito era ir à casa de banho e fazer parte da minha dignidade tentar limpar... e consegui a muito custo.

Anos depois, a debilidade e a dependência deixaram marcas, estão onde ninguém vê, mas Alexandra ainda as sente em memória, daquela que dura, que nunca muda.

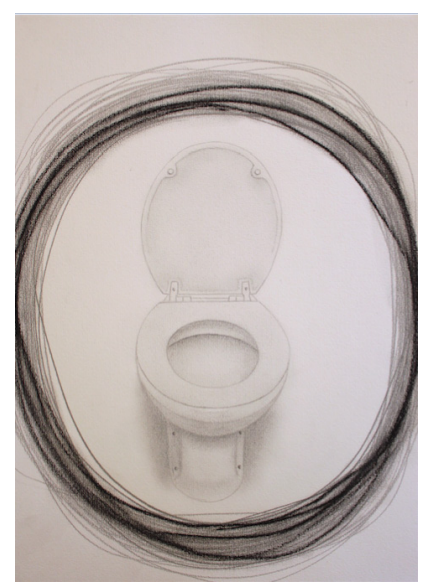

Figura 5: Dignidade... tentar limpar [Grafite e carvão sobre papel]

Fonte: Susana de Noronha e Alexandra Silva (2017)

"Lembro-me, passadas duas ou três semanas, de começar a ficar ansiosa pelo resultado da análise". Alexandra soube o resultado por "portas travessas" e por telefone, pela voz de uma amiga. Alexandra tinha cancro da(s) mama(s), um carcinoma ductal 
invasivo na mama direita e um in situ na esquerda. Nenhuma das intervenções foi profilática, a mastectomia subcutânea também foi extrativa. Já recuperada de dores maiores, Alexandra recebia um telefonema do IPO, convocada para uma consulta daí a três semanas, para falar dos resultados e tratamentos seguintes. Apontaram-lhe uma data, mas não disseram mais nada, deixando-a pendurada por 21 dias, mais de 500 horas de espera, de ansiedade sentada.

Aí foi o meu grande problema! Quando me preparo para o pior, a coisa se vier, pronto, eu já sabia. (...) Porque eu acreditei nisto... eu vou agora tirar as mamas, já estou aqui a fazer uma coisa tão radical para depois não ter que me preocupar com mais nada! Eu achava que tirava as mamas e que ia à minha vida normal. (...) Eu consegui ali perceber que ia fazer quimioterapia e não estava nada preparada para aquilo!

Alexandra tinha medo do "mal-estar, do desconforto, da perda da qualidade de vida, dos efeitos secundários", já os conhecia de perto, agarrados às mulheres da sua família. "O que mais medo me fez... foi perceber que aquilo não ia ter fim nunca mais. la-me acompanhar para o resto da vida". Alexandra não viu a quimioterapia como o último tratamento ou o fechar de um ciclo, mas como o reinício de uma coisa que nunca acaba, um círculo fechado à volta das mamas e da sua vida. Porque "o pior são as esperas", Alexandra soube naquele momento que um rasto de angústia e incerteza estaria consigo para o resto dos dias, a todo o momento, mesmo em horas felizes.

Alexandra esperou pela quimioterapia, sabendo que o pior estava por vir, só não sabia que seria o cateter a puxar-lhe a maior dor. Com seis ciclos pela frente, "o mínimo, o que está protocolado", Alexandra era espetada a cada ida, no mesmo sítio, o braço esquerdo.

Houve momentos de mal estar, aí eu fui-me muito abaixo. Mas a pior coisa da quimioterapia, o que mais me custou, era a porcaria dos cateteres! Eu começo a sentir-me mal quando falo disto... foi um momento de dor horrível e eu nesse dia quis desistir! Eu estava na cadeira... tinha uma proposta de seis ciclos. Estou no quarto... eu não aguento outra vez mais três... e disse, eu vou-me embora, eu não consigo!

Depois de várias tentativas furadas da enfermeira, entre pulso e braço, Alexandra fez o quarto ciclo, mas a dor do cateter enfiado na veia invadia tudo, corpo, cadeira e mundo. A seu pedido, a médica que a acompanhava encurtou o plano de tratamento, avaliou o risco e cancelou os dois últimos ciclos. Até esse dia, Alexandra esteve à espera da decisão, ansiosa, quase parada, tentando levar a vida. Quando soube que não haveria quinto nem sexto ciclo pensou "pronto, agora acabou, hoje é o dia em que acabou... mas depois não acabou nada!". 


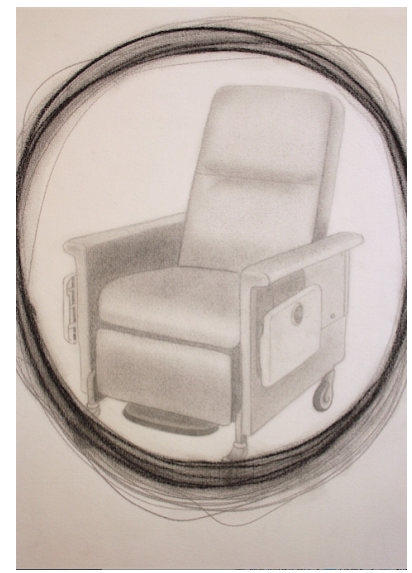

Figura 6: O que mais me custou, a porcaria dos cateteres [Grafite e carvão sobre papel]

Fonte: Susana de Noronha e Alexandra Silva (2017)

\section{ESPERAR PELO QUE HÁ DE VIR: DO IMPLANTE MAMÁRIO À OOFORECTOMIA}

"Depois és tu que não és a mesma, porque já aconteceram muitas coisas. O corpo não é o teu! Tu não te identificas com aquela pessoa que vês no espelho". Alexandra não se conseguia enfiar na mulher que aparecia refletida, sabia que não voltaria a ser a mesma, mas podia ser refeita, um pouco mais perfeita, voltar a ter mama direita. Reconstruir é recomeçar e Alexandra voltou à espera e à ansiedade, tentando marcar novas cirurgias, fazer a mama acontecer. "Eu quero tudo tão para ontem... porque preciso ter um fim nas coisas para virar a página, e eu vivia nessa ansiedade". Nada aconteceu "tão cedo quanto esperava", mas Alexandra diz que o processo de reconstrução "foi muito fácil e até relativamente rápido, talvez um ano e meio" para a mama estar acabada, do expansor ao implante. Mas foi Alexandra que acelerou tudo, passava pelo hospital, fazia pressão, pedia uma data, "sempre a chatear". Com a troca das próteses pelo implante de silicone, Alexandra queria fechar a estória do cancro, reconstruir-se, guardar o que ficou e esquecer o resto. "Nessa expectativa de pôr termo à coisa... de chegar ao fim... aqui, na minha lógica, acabava a quimioterapia, acabava os comprimidos, acabava as picas". No dia 10 de novembro de 2010, o implante ficou fechado com ponto e nó, com linha de sutura, mas o carcinoma da mama, a doença toda, ainda guardava algumas surpresas desagradáveis.

Já sem cancro na mama, mas medicada, entre injeções mensais e comprimidos, Alexandra pediu a transferência do seu processo para Lisboa, a sua nova cidade, para acabar o plano de tratamento. Foram as frases do oncologista que recebeu o processo que lhe tiraram tudo, até a esperança.

Está a fazer este tratamento para quê? Não se justifica. Porque é que não tira logo os ovários? Ainda para mais, tem um tumor que não lhe oferece garantias de cura! (...) Eu parei a olhar para ele... está-me a passar um atestado de óbito! Foi no dia 9 de dezembro. Era a primeira vez que me falavam em morte! 
O acontecimento, a consulta do dia 9, é hoje uma "memória marcante", daquelas que ninguém esquece, virou-lhe os dias ao contrário e os anos que tinha pela frente. "Comecei a aperceber-me de que aquilo não ia ter um fim, que isto ia estar sempre presente. Sinto que sou uma bomba relógio. Tenho a certeza que mais cedo ou mais tarde isto vai voltar". A consulta não foi de rotina, a estória mudou de título, voltou ao princípio, sem fim. "Pois, realmente é dos mais difíceis!". Na frase da sua médica, reforçando a afirmação do novo oncologista, o seu cancro parecia algo novo, diferente e pior. Alexandra não gosta de esperas, mas gosta de esperar pelas coisas, contar com elas. Durante meses, pensou na morte, no tempo gasto e perdido, sem ganho.

Ali, naqueles meses, eu comecei a pensar... então não valeu de nada aquilo que eu andei a fazer!? Foi uma fase muito complexa da minha vida, de muitas perguntas, de uma vida muito desregrada. Pensei em suicidar-me e coisas desse género! Foi um período mesmo muito difícil.

Com a ajuda de medicação, a minha vida pessoal e profissional foi estabilizando... e eu fui olhando sempre o lado bom das coisas. Houve uma grande excitação com a aproximação do final dos tratamentos. (...) Mas eu acreditava que me iam autorizar a cirurgia do ovário logo a seguir e não estava preparada para levar a nega.

Alexandra ainda em espera, voltou a olhar para o relógio numa luta contra o tempo para tirar os ovários. Portadora de mutações BRCA1/2, com um cancro hormonodependente, Alexandra tinha urgência em tirar os ovários, sabia a importância que tinha a cirurgia para a sua sobrevivência. Mas o protocolo dita que não se fazem ooforectomias a mulheres antes dos 35 anos. "O termo que vem no protocolo é 'ter a vida reprodutiva resolvida'. Eu não quero sequer ter uma vida reprodutiva! Não querer também é uma opção!". Esperar pela segunda metade da sua terceira década era muito tempo, um intervalo que alargava o risco de uma segunda doença. Em dezembro de 2013, Alexandra ainda esperava pela cirurgia, sem data marcada, sem "ver isto arrumado". Quem tomava as decisões, seguindo o protocolo, continuava à espera do tal aniversário, desafiando a estatística, $60 \%$ de probabilidade de cancro do ovário. Alexandra vivia mais um momento de espera ansiosa, deixada "em suspenso", e embora não quisesse "estar a pensar nisto o dia inteiro", os ovários estavam sempre na sua cabeça, no lugar errado.

Meio ano depois da nossa conversa, Alexandra anunciava a sua última cirurgia nas redes sociais. "Amigos/as vou ser castrada. Preventivamente, claro. Tudo como eu desejava. É menos uma preocupação". No dia 13 de maio, num autorretrato feito no IPO de Coimbra, Alexandra mostrava a pulseira onde as palavras "Int. Ginecologia" a colocavam no sítio certo. Alexandra esperou seis anos por este dia, fazia 35 anos um mês depois, mostrando que há papéis e protocolos que rejeitam pedidos e desejos, adiam alegrias, prolongando a espera com muitas cadeiras.

Eu quero viver tudo! Quero experimentar tudo! Quero conhecer todas as pessoas do mundo e ir a todos os sítios do mundo, por isso a minha vida 
não pode terminar já. (...) Eu tenho sempre novas coisas para fazer e para isso eu tenho que viver, tenho de me cuidar.

Alexandra fez escolhas e refez rotinas, os dias do "ritmo acelerado, desregrado e pernicioso" estão para trás, gosta de aproveitar divertimento e trabalho com conta e medida, apreciando os detalhes.

Tenho mais prazer em viver. Vivo mais insegura, no sentido em que estou mais preocupada no quotidiano, mas também sinto mais prazer a fazer as coisas, porque faço também muito mais coisas. (...) Devíamos todos aproveitar melhor e seguir o lema do seize the day, do carpe diem, não viver todos os dias como se fossem o último, mas viver todas as semanas como se fossem a última.

Apesar das esperas e perdas, Alexandra fez-se maior, ganhou idade, experiência e conhecimento, sabe viver melhor, "faz mais coisas", dá outros usos e sentidos ao tempo.

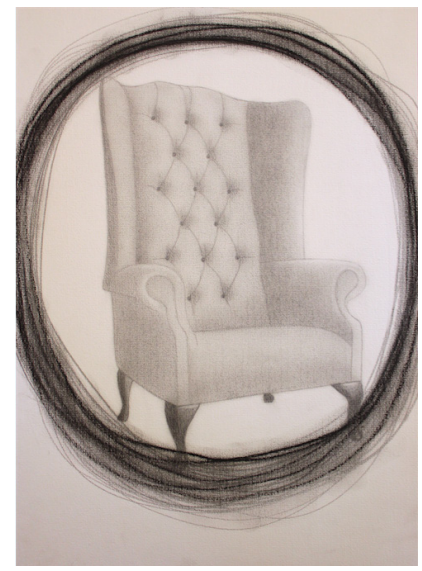

Figura 7: Eu quero viver tudo, experimentar tudo! [Grafite e carvão sobre papel] Fonte: Susana de Noronha e Alexandra Silva (2017)

\section{AS SETE CADEIRAS: DESENHAR O TEMPO E A DOR DA ESPERA}

"O pior é a espera!". Enquanto transcrevia as palavras de Alexandra, o tempo emergia como o elemento estruturador da sua experiência e narrativa, datada de forma precisa, do mês que corria ao dia da semana, numa sequência de acontecimentos frequentemente ligados à paragem em determinadas cadeiras ou assentos. Para desenhar a estória de Alexandra, os eventos e memórias mais marcantes, dei forma a sete cadeiras vazias, lembrando os assentos onde o cancro e todas as esperas aconteceram. As cadeiras remetem para objetos reais e momentos concretos referidos por Alexandra, diretamente ou nas entrelinhas da estória contada, usando-as depois como metáforas para o tempo passado em espera, procurando uma imagética heurística para uma abordagem do cancro da mama hereditário, dos testes pré-diagnósticos à espera diária pela recidiva, agarrando a ausência de doença e sintomatologia, o chamado estado de remissão. 
Cinco das sete cadeiras desenhadas para Alexandra representam dias, semanas, meses e anos de espera, onde tudo pára e piora (Figuras 1, 2, 3 e 4). As restantes três representam o tratamento e a resistência, cirurgias, ciclos de quimioterapia e a vida que se faz em casa, no trabalho e na rua (Figuras 5, 6 e 7), onde a estória acelera.

O primeiro desenho dá forma à cadeira da sala de espera onde Alexandra se sentou antes de ouvir o resultado do exame genético e de receber o papel com as mutações $\mathrm{BRCA}_{1} / 2$. Eu não sou um papel! relembra que depois levantada da cadeira, relatório e protocolo "abalaram" corpo e tempo, a sua "perceção do futuro" mudou, encolhendose. Nesta cadeira, Alexandra esperou sem saber que tudo iria mudar, corpo, rotinas e planos para o tempo à frente. O segundo desenho dá forma a todas as cadeiras dos consultórios médicos onde Alexandra se sentou, esperando pelas melhores notícias, nem sempre preparada para aquelas que ouvia, desejando sempre chegar ao fim de exames e análises, sem necessidade de tratamentos, lembrando que o pior é esperar. O desenho Dez minutos de espernear e gritar dá forma ao assento do carro onde esperou pela resposta que chegava do outro lado do telemóvel, vinda de Lisboa, o resultado da biopsia, a confirmação do cancro. Nesse assento, Alexandra esperneou e gritou até se lembrar que sempre tinha esperado pelo cancro, do passado ao presente, agarrar o volante da vida, aquilo que estava por vir, dependia de si. A quarta cadeira e desenho, O pior é contar aos pais!, encosta-se à mesa da sala da sua família, onde esperou pelo fim da refeição, dando a notícia da sua doença. Um dos piores momentos da sua estória agarra-se a esta cadeira, pôr o cancro na mesa, em pratos limpos, dizer aos pais. O desenho lembra que nunca existe o momento correto ou o tempo certo para dar uma má notícia. Dizer que se tem um cancro é sempre uma má experiência e uma má memória, agarrada ao dia, ao lugar e ao objeto onde a conversa se deu.

O quinto desenho deixa-nos espreitar o assento e o fundo de todas as sanitas, os momentos nas casas de banho do hospital, depois das cirurgias, cortada, cosida e dorida, mantendo a dignidade de se limpar sozinha. O tampo aberto lembra a "debilidade" e a força necessária para sentar e dobrar o corpo, sem ajuda dos outros, durante o pós-operatório, o duro tempo que demora o recobro. No desenho O que mais me custou, a porcaria dos cateteres, a cadeira da quimioterapia aponta para outro objeto, para o cateter, para a sua "brutalidade", para os minutos de espera antes da espetadela, da pele furada de dor. Antes, durante e depois do tempo passado na cadeira almofadada, Alexandra não tinha descanso nem conforto, só "mal-estar, dores horríveis", vontade de desistir. O último desenho, Eu quero viver tudo, experimentar tudo! inspira-se na poltrona de uma personagem adoecida e falecida num dos seus filmes de animação preferidos, Up, lembrando que a vida é feita de pé, com uma lista de "stuff I'm going to do". Enquanto espera, sem saber se a recidiva virá, Alexandra não está na cadeira nem tenciona ficar sentada, escolhe levantar-se e sair, quer viver, fazer e conhecer mais coisas, continuar a crescer. Alexandra sabe que a mutação genética é inescapável, um círculo fechado "para o resto da vida". Dentro do risco circular deste ciclo, as sete cadeiras cabem em qualquer futura semana, de segunda a domingo. Contudo, os desenhos carregam a esperança de que as mesmas não voltem a ser usadas nos anos por vir. 
Só o desenho etnográfico criativo e a imaginação poderiam juntar algumas das cadeiras usadas por Alexandra Silva, lembrando a resistência necessária para sentir a dureza quieta de todas elas, preto no branco, mesmo daquelas que parecem cómodas. No seu conjunto, os desenhos também têm a ambição de desmanchar algumas das piores consequências da doença oncológica hereditária, satisfazendo um dos maiores desejos de Alexandra. As sete cadeiras carregam a vontade de arrumar a sua estória, uma cadeira para cada dia da semana, uma sequência já fechada, deixada no passado. Para contrariar a espera, a sua estratégia de resistência consistiu num aceleramento da vida e dos seus acontecimentos, levantando-se da cadeira, uma vontade repetida e representada nas ilustrações. Os desenhos lembram que Alexandra ainda espera mas nunca pára, não fica sentada. Estas cadeiras ficarão vazias, sem gente doente, sem o peso futuro de nenhuma mulher. Alexandra deu-me algum do seu tempo, três horas e trinta e três minutos de entrevista e conversa. A partilha das suas palavras e experiência vivida, permitiu a escrita ilustrada de um ensaio sobre o seu cancro, dando sentido ao tempo, à doença e a dor da espera com desenho etnográfico criativo.

\section{CONSIDERAÇÕES FINAIS}

Resumindo esta estória e experiência, quais as reflexões que podemos retirar da mistura de conhecimentos incorporados, antropológicos e criativos relativamente ao tempo, à espera e ao cancro da mama hereditário? Quais as experiências, sentidos e usos encastrados no tempo relativamente às causas, sintomas, diagnóstico, tratamento e consequências do cancro de Alexandra? Nas narrativas de cancro há normalmente um "depois" do diagnóstico e da doença, mas nas experiências de cancro hereditário, o "antes" emerge como momento relevante para a sua compreensão. O "antes" liga-se à etiologia de carcinomas, às causas definidas por mutações genéticas, explicando o princípio da doença. O "antes" aponta para os cancros que se esperam, num quotidiano já preenchido por exames e consultas, desmontando a ideia do diagnóstico como uma ruptura no tempo (Trusson, Pilnick \& Roy, 2016), separando a pessoa que se era daquela que se redefine como doente. A estória de Alexandra mostra a vontade de antecipação da oncologia, os dados puxados a agulha do histórico da família, esperando o cancro, detectado a tempo. Mas, embora o seu cancro fosse esperado, com raízes no passado e nos corpos das mulheres que a antecederam, nem Alexandra nem a família o esperavam tão cedo, aos 28 anos. Desencaixado da idade socioculturalmente preconcebida como a esperada para o desenvolvimento de uma doença grave (Pecchioni, 2012), o seu cancro acabou por ser vivido como imprevisto, difícil de assumir.

Relativamente ao tratamento oncológico, a sua experiência e narrativa aponta para lá dos efeitos desejados e secundários de cirurgias, ciclos de quimioterapia e reconstruções. Embora alguns dos piores momentos se agarrem aos cateteres, à sua entrada na pele e nas veias, Alexandra secundariza "o lado físico da coisa". Alexandra afirma que o "pior é a espera, a ansiedade das vésperas", ferindo mais do que a dor. Os tratamentos demoram e tardam, adiam o fim da estória de doença, param a vida. Durante os seis 
anos de tratamento, esperou pelo dia das mastectomias, esperou para saber o tipo e o estádio do(s) carcinoma(s) que tinha. Esperou para saber se faria quimioterapia, esperou pelo momento da entrada de cada cateter, esperou pelo fim da dor, pela saída da agulha. Esperou um ano e meio para marcar e fazer cirurgias plásticas e acabar reconstruções. Esperou seis anos para tirar os ovários, esperou mais de meia década pela decisão médica e ainda espera pelo resultado de cada exame e consulta de rotina. As suas palavras retiram as transformações físicas das linhas centrais da narrativa, minimizando a perda das mamas, a queda de cabelos, as feridas que se abrem ou as cicatrizes que ficam, distanciando-se de outras reflexões sobre a doença oncológica mamária (DeShazer, 2015; Noronha, 2009). Alexandra "queria tudo para ontem", fechar a estória da doença era a sua prioridade máxima, mais do que reconstruir as mamas ou nivelar o peito. Acabar com a dor da espera é contudo uma tarefa adiada, pois ainda carrega as mutações e a probabilidade de uma recidiva. O cancro da mama hereditário estende-se assim num continuum temporal, vivido em família entre parentes adoecidas, esperado no passado enquanto portadora de mutações, revivido no corpo durante o diagnóstico e tratamento, e ainda presente enquanto ameaça futura.

O tempo também se revela essencial à resistência, enquanto processo estendido à vida, da casa ao trabalho, passando pelos amigos e pela família. Alexandra esperou mas nunca parou, contou a estória a toda a gente, em conversas, blogues, fotografias, redes sociais e televisões. "Fazer alguma coisa com esta doença" foi uma estratégia de resistência, usada em proveito próprio e para ajudar os outros. Falar do cancro ainda hoje ajuda, dá sentido à sua experiência, passando conhecimento a quem ouve. Durante a doença, viveu tudo intensamente, comeu, bebeu, saiu com amigos, foi a festivais, viu séries e filmes, leu livros, ouviu álbuns e canções. Arranjou emprego e casa, namorou, casou-se, conheceu gente e sítios, passeou e viajou. Para resistir, Alexandra contrariou as esperas do tratamento, preenchendo o tempo, aproveitando os momentos, acelerando a vida e a língua, procurando experiências, falando muito. A experiência e estória de Alexandra atravessa múltiplas dimensões de temporalidade, da forma como a sentimos, entendemos e gerimos na ligação com a doença, antes, durante e depois do cancro. Embora o tempo nunca pare, Alexandra descreve momentos de paragem, na espera por resultados e avanços no seu processo de doença, gerados pela interrupção, lentidão, demora, atraso e adiamento de tratamentos, contrastando com a sua pressa e urgência em fechar a estória do cancro. Alexandra continua à espera, o cancro não acaba, a mutação "está no seu ADN", inscrita em todo o seu tempo de vida. Ainda receia a recidiva, uma estória repetida, um futuro mais curto, apagada dos outros, da História maior. Embora tenha a mutação genética, vigiada num calendário cíclico de exames de rotina, Alexandra também espera o melhor, uma vida até ser "velhota"./

\section{FinANCiAmento}

A presente publicação resulta dos apoios da Fundação para a Ciência e a Tecnologia portuguesa, ao abrigo do Projeto Estratégico (UID/SOC/50012/2019); da Norma 
Transitória (DL57/2016/CP1341/CTo012); e do Programa Operacional Capital Humano $(\mathrm{POCH})$, comparticipado pelo Fundo Social Europeu e por fundos nacionais do Ministério da Ciência, Tecnologia e Ensino Superior (MCTES) - bolsa de Investigação de pós-doutoramento Ref.: SFRH/BPD/88239/2012.

\section{REFERÊNCIAS}

Adam, B. (1994). Time and social theory. Cambridge: Polity Press.

Adam, B. (2013). Timewatch: the social analysis of time. Cambridge: Polity Press.

Araújo, E. (2012). A espera e os estudos sociais do tempo e da sociedade. In E. Araújo \& E. Duque (Eds.), Os tempos sociais e o mundo contemporâneo: um debate para as Ciências Sociais e Humanas (pp.9-25). Braga: CECS.

Banks, M. \& Zeitlyn, D. (2015). Visual methods in Social Research. Londres: Sage Publications.

Burke, N. J. \& Mathews, H. F. (2017). Returning to earth: setting a global agenda for the Anthropology of cancer. Medical Anthropology, 36(3), 179-186.

Csordas, T. (Ed.) (1994). Embodiment and experience: the existential ground of culture and self. Cambridge: Cambridge University Press.

Dean, M. (2016). It's not if I get cancer, it's when I get cancer: BRCA-positive patients (un)certain health experiences regarding hereditary breast and ovarian cancer risk. Social Science Q Medicine, 163, 21-27.

DeShazer, M. K. (2015). Mammographies: the cultural discourses of breast cancer narratives. Ann Arbor: University of Michigan Press.

Finkler, K. (2003). Illusions of controlling the future: Risk and genetic inheritance. Anthropology Q Medicine, 10(1), 51-70.

Gell, A. (1998). Art and agency: an anthropological theory. Oxford: Clarendon Press.

Hall, E. T. (1984). The dance of life: The other dimension of time. Nova lorque: Anchor Books.

Hallowell, N. \& Lawton, J. (2002). Negotiating present and future selves: managing the risk of hereditary ovarian cancer by prophylactic surgery. Health, 6(4), 423-443.

Hauge, B. (2015). Re-designing the everyday: the use and perception of time among cancer patients combining work and treatment. Time Q Society, 25(2), 193-212.

Hesse-Biber, S. (2014). Waiting for cancer to come: Women's experiences with genetic testing and medical decision making for breast and ovarian cancer. Ann Arbor: University of Michigan Press.

Mattingly, C. \& Garro, L. C. (Eds.) (2001). Narrative and the cultural construction of illness and healing. Berkeley CA: University of California Press.

Mendes, F. (2004). A herança dos 'mal-nascidos': dos filhos do passado aos filhos da ciência. Revista Crítica de Ciências Sociais, 70, 57-79.

Miranda, N. \& Portugal, C. (2016). Portugal doenças oncológicas em números - 2015 (Programa Nacional Para as Doenças Oncológicas). Lisboa: Direção-Geral da Saúde. 
Mulcahy, C. M., Parry, D. C. \& Glover, T. D. (2010). The 'patient patient': the trauma of waiting and the power of resistance for people living with cancer. Qualitative Health Research, 20(8), 1062-1075.

Noronha, S. (2009). A tinta, a mariposa e a metástase: a arte como experiência, conhecimento e acção sobre o cancro de Mama. Porto: Afrontamento.

Noronha, S. (2015). Objetos feitos de cancro: mulheres, cultura material e doença nas estórias da arte. Coimbra: Almedina.

Noronha, S. (2019). Cancro sobre Papel: estórias de oito mulheres portuguesas entre palaura falada, arte e ciência escrita. Coimbra: Almedina.

Pecchioni, L. L. (2012). Interruptions to cultural life scripts: cancer diagnoses, contextual age, and life narratives. Research on Aging, 34(6), 758-780.

Rees, S. (2016). Am I really gonna go sixty years without getting cancer again? Uncertainty and liminality in young women's accounts of living with a history of breast cancer. Health, 21(3), 241-258.

Schneider, A. \& Wright, C. (Eds.) (2005). Contemporary art and anthropology. Oxford: Berg Publishers.

Trusson, D., Pilnick, A. \& Roy, S. (2016). A new normal? Women's experiences of biographical disruption and liminality following treatment for early stage breast cancer. Social Science Q Medicine, 151, 121-129.

Zerubavel, E. (1979). Patterns of time in hospital life. Chicago: University of Chicago Press.

\section{NotA BIOGRÁFICA}

Susana de Noronha é antropóloga, doutorada em sociologia e investigadora do Centro de Estudos Sociais da Universidade de Coimbra. Foi distinguida com o "Prémio CES Para Jovens Cientistas Sociais de Língua Portuguesa 2007" e com o "Prémio Bernardino Machado 2003" de Antropologia pela Universidade de Coimbra. É autora dos livros A tinta, a mariposa e a metástase: a arte como experiência, conhecimento e ação sobre o cancro de mama (2009, Afrontamento); Objetos feitos de cancro: mulheres, cultura material e doença nas estórias da arte (2015, Almedina); Cancro sobre papel: estórias de oito mulheres portuguesas entre palavra falada, arte e ciência escrita (2019, Almedina). Enquanto fazedora de textos e ciência, é também letrista publicada e criadora de ilustração científica em fotografia, pintura e desenho etnográfico criativo.

ORCID: https://orcid.org/o000-0003-1823-4342

Email: susananoronha@ces.uc.pt

Morada: Universidade de Coimbra, Centro de Estudos Sociais. Colégio de S. Jerónimo, Largo D. Dinis, Apartado 3087, 3000-995 Coimbra, Portugal

* Submetido: 10/10/2018

* Aceite: $20 / 01 / 2019$ 